\title{
POLICIAIS E POPULARES: EDUCADORES, EDUCANDOS E A HIGIENE SOCIAL
}

\author{
VALTER Martins
}

\begin{abstract}
RESUMO: O insalubre Largo do Jurumbeval, em Campinas, constituiu durante a segunda metade do século XIX importante espaço de trabalho, diversão e moradia popular. A promíscua aglomeração de pessoas: escravos, libertos, imigrantes e nacionais pobres, inquietava as autoridades que, por meio da ação da polícia, procuravam limitar, controlar e ordenar os movimentos de pessoas vistas como perigosas à sociedade, por seu comportamento considerado imoral e escandaloso. Nessa tentativa de realizar uma higiene social, por vezes, a própria polícia acabava representando um papel ambíguo, ao praticar os mesmos atos que devia reprimir. Resgatar alguns momentos dessa "didática" policial na vida das classes populares constitui o objetivo deste artigo.
\end{abstract}

Palavras-chave: Educação. Vida urbana. Classes populares. Higiene social.

\section{Police InVOlVEMENT IN THE MORAL EDUCATION of the lower Classes in $19^{\mathrm{TH}}$ Century at Campinas}

ABSTRACT: Largo do Jurumbeval, in the city of Campinas, was considered unhealthy and even dangerous place during the second half of the $19^{\text {th }}$ Century, although many lower class individuals either lived or worked there. The uncontrolled conglomeration of such "undesirable" people (blacks, both free and slave, immigrants and other poor Brazilians) was seen as a threat by the authorities, and attempts were made to control these immoral and scandalous individuals by limiting their contact with each other and their access to the area. One of the solutions proposed by county officials involved the moral education of these individuals, to be provided

* Doutor em História Social pela Universidade de São Paulo (USP) e professor de História da Educação na Pontifícia Universidade Católica do Paraná (PUC-PR). E-mail: batvalter@uol.com.br/vmartins@unicamp.br 
by the police. In these attempts at moral education, however, the police played a rather ambiguous role, as they often practiced those acts which they were supposed to curtail. The present paper was designed to recuperate some of these "police teachings" and their effect on the lives of the people involved.

Key words: Moral education. Education. Urban life. Lower classes.

$\mathcal{D}$ urante a segunda metade do século XIX, além de notórios problemas sanitários, o Largo do Jurumbeval, situado na cidade de Campinas, apresentava constantes problemas no que dizia respeito à ordem e ao decoro públicos. Aos brejos, ao lixo e seus temidos miasmas, ${ }^{1}$ juntavam-se os moradores e freqüentadores daquele lugar público. Apesar de acumular qualidades nada adequadas tanto para habitação como para o convívio social, aquele espaço constituía local bastante concorrido, principalmente após a instalação de dois chafarizes. Seu movimento e "animação" ajudaram a desbravar e incorporar aquela área agreste ao uso da cidade, mesmo que nesse processo muita coisa considerada reprovável tenha ocorrido por ali (Martins, 2001).

Mesmo antes dos chafarizes, inaugurados no início na década de 1870, o Largo do Jurumbeval ostentava uma efervescente vida social e uma variada gama de estripulias. Aquele lugar que abrigaria um imponente mercado a partir de $1908^{2}$ funcionou nas décadas que o precederam como um dos principais pontos de reunião de negros na cidade, tanto cativos como libertos. Junto dos chafarizes, escravos, lavadeiras, aguadeiros ou simplesmente gente em busca de um gole d'água ou de uma prosa viviam um cotidiano bastante agitado e barulhento, no qual certamente não havia um dia igual ao outro. Ao mesmo tempo em que realizavam seu trabalho, trocavam informações, travavam disputas, divertiam-se e namoravam. Tudo isso num estilo bastante particular que deixava muita gente indignada:

(...) dizem-nos pessoas de todo o crédito que costuma haver aglomeração de pretos, os quais, sem respeito ao decoro público e muito menos às famílias, ali dão-se a cenas pouco edificantes e nada de acordo com a boa moral, já pelas palavras obscenas e já pela algazarra desenfreada e outros atos análogos. (Gazeta de Campinas, 3/4/1873, p. 2)

A escravidão, dura que era, tinha seus momentos de descontração e alegria, ainda que fugazes. Essas brechas de liberdade, por estreitas que fossem, eram sempre aproveitadas pelos escravos na recu- 
sa e na resistência ao controle total sobre suas vidas. Como bem verificou Sidney Chalhoub no Rio de Janeiro imperial, os escravos, quando possível, procuravam "viver sobre si" (Chalhoub, 1990, p. 212-233). Que mais poderia ser tão desconcertante ou mais subversivo que o riso de um escravo?

Naqueles anos em que a cidade enriquecida pelo ouro verde se aburguesava (Lapa, 1996), certos hábitos, atitudes e vocabulários até então considerados comuns passaram a ferir sensibilidades e a preocupar autoridades e chefes de família. Desejava-se então uma cidade educada, limpa e saudável. A educação daquela gente inculta, a promoção de uma higiene social, purgando tudo aquilo que não mais poderia ser tolerado, passava muitas vezes pelas ações dos policiais da cidade que, como seus "educandos", também pertenciam às classes populares. As reações daqueles que se buscava educar não foram poucas. ${ }^{3}$

Antes mesmo que os galos encerrassem sua cantoria na madrugada, o movimento já era grande junto dos chafarizes do Jurumbeval. Escravas equilibrando elegantemente jarros de barro na cabeça ou conduzindo burros com pipas de madeira ao lombo buscavam a água necessária ao consumo na casa de seus senhores. Logo depois, em meio às névoas matinais que se dissipavam, surgiam daqui e dali as lavadeiras com suas coloridas e volumosas trouxas, para mais um dia de muitas esfregadas e conversas em alto volume. Aos poucos, iam chegando outras pessoas que nem sempre tinham no trabalho o único motivo para estarem ali. Com o avançar do dia, o cenário com suas quase sempre mesmas e anônimas personagens se completava, preocupando vereadores, ruborescendo os mais pudicos. Condenavam-se as reuniōes de "ociosos", as "vozerias" e os "atos de desenvoltura". Afinal, bastava "o estado físico daquele largo com seus imundos depósitos de lixo, sem que os vizinhos e os transeuntes sejam também incomodados moralmente". Dizia-se que o ajuntamento promíscuo entre escravos e livres não era o que mais incomodava a vizinhança e sim o vocabulário por demais desinibido utilizado naqueles encontros. Era preciso "educar" aqueles abusados impertinentes. Para tanto, convocava-se a polícia, e até mesmo os inspetores de quarteirão, na tentativa de controlar o mais rebelde órgão do corpo humano, a língua (O Constitucional, 19/8/1874, p. 3. Diário de Campinas, 17/11/1876, p. 2).

Mas os problemas não se resumiam a isso. Dependendo diretamente da água dos chafarizes para seu trabalho, lavadeiras e 
aguadeiros estavam lado a lado todos os dias, o que não significava que sua convivência fosse sempre de paz e harmonia. A água era um bem precioso e, em uma cidade populosa que ainda carecia de uma rede de abastecimento domiciliar, seu uso e distribuição eram objeto de disputas porque para muitas pessoas o acesso a ela garantia a própria subsistência. Assim, as tensões entre aqueles trabalhadores das bicas e dos chafarizes da cidade eram corriqueiras, gerando inúmeras reclamações:

Queixam-se os moradores do Largo do Jurumbeval das cenas repugnantes que diariamente são obrigados a presenciar, por parte dos carroceiros que conduzem água e pretas que lavam roupa naquele largo. As constantes brigas e revoltante obscenidade que se dão entre aquela gente obrigam à clausura as famílias que ali moram. (Diário de Campinas, 2/10/1879, p. 2)

Quando os jornais não se referiam ao permanente mau estado sanitário do Jurumbeval, quase sempre estavam às voltas com outras ocorrências no largo como prisōes, brigas, desordens, espancamentos, algazarras, imoralidades, agressão e, muito raramente, assassinato. Tais palavras eram normalmente utilizadas como chamadas para as notícias que escandalizavam vários leitores daqueles tempos. Muitos campineiros, orgulhosos de sua rica e bela cidade, viam com preocupação aquela situação. A polícia deveria não apenas cuidar do patrimônio dos cidadãos e manter a ordem, mas exercer também um papel educador da população mais pobre. Assim como ocorreu na Inglaterra vitoriana, os policiais passaram a reprimir energicamente velhos hábitos populares até então tolerados, tentando impor limites ao que seria aceito. Como na Europa, esses limites foram o resultado do confronto entre o novo padrão de conduta que se constituía e antigas práticas sociais ainda em voga na sociedade (Storch, 1985).

Desejava-se que a polícia cumprisse um papel educativo ao ditar regras de convívio e coibir açóes consideradas impróprias. Muitos dos encontros entre policiais e populares eram marcados pela violência: era uma verdadeira "pedagogia do cassetete". Por volta do meiodia de 20 de abril de 1886, a negra Cândida lavava roupa no chafariz do Largo do Jurumbeval quando foi "provocada por uns moleques aos quais respondeu com palavras ofensivas da moral pública". Por esse "crime" ou grande "falta de educação", acabou "presa por algumas praças que a maltrataram com murros e pranchadas, deixando-a toda ensangüentada" (Diário de Campinas, 21/4/1886, p. 2). 
Mas a ação da polícia naquele lugar da cidade, como em outros, nem sempre ocorria sem maiores resistências dos populares. Ao prenderem alguns indivíduos por "terem se enganado na medida e andarem pela rua a dizer coisas feias", os policiais enfrentaram o protesto de vários amigos dos presos que entenderam ser a prisão um grande desaforo. Uma patrulha acabou dispersando o grupo que se retirou "atirando contra as praças algumas pedras que não acertaram" (Diário de Campinas, 21/11/1876, p. 2). Eram as relações entre as pessoas, presentes na sociedade, resistindo ao novo padrão de comportamento burguês que rapidamente ganhava terreno na cidade.

Entre os hábitos populares mais atacados pela imprensa e que mereciam a atenção das autoridades estava o consumo do álcool, constantemente associado às desordens no Jurumbeval. As histórias envolvendo bebedeiras eram comuns. Depois de certo tempo "matando o bicho" em algum dos muitos estabelecimentos do famoso Largo, por volta das 19:30 de 30 de setembro de 1877, os italianos Januário Concilio, Vicente Concilio e Nunciato Galiano caminhavam tropegamente quando resolveram molestar uma mulher que passava. Avisada, a polícia chegou em tempo e levou todos ao xadrez, onde puderam curar a carraspana e, quem sabe, a falta de modos. Em uma sexta-feira de 1880, foi a vez do forro Saturnino de tal. Ao exagerar na caninha e após provocar grande distúrbio "(...) foi apresentar sua cantoria na enxovia" (Diário de Campinas, 2/7/1877, p. 2. Gazeta de Campinas, 2/7/1877, p. 2; 23/4/1880, p. 2).

Entre os dedicados consumidores da cachaça encontravam-se muitas mulheres que, sob seus efeitos, atentariam contra os chamados bons costumes, que cada vez mais se buscava preservar. A Gazeta de Campinas informava em agosto de 1880 que as cenas de imoralidade praticadas por várias moradoras do Jurumbeval eram freqüentes: "Essas mulheres se embriagam e fornecem espetáculos de um realismo desesperador, impedindo deste modo as famílias de por ali transitarem. À polícia recomendamos essas bacantes”. As coisas continuaram no mesmo ritmo e, dois meses depois, o mesmo jornal solicitava novamente à polícia que chamasse à "ordem aquelas mulheres que ali embriagam-se quotidianamente promovendo cenas que revoltam a moral" (Gazeta de Campinas, 12/8/1880, p. 2; 15/10/ 1880 , p. 2). Uma eficiente ação repressiva tornava-se inadiável. A boa moral precisava ser ensinada e mantida a todo custo.

$\mathrm{Na}$ verdade, a cachaça era apenas um dos ingredientes de toda uma situação vivida por muitos dos habitantes da cidade que se pre- 
tendia reordenar por meio dessa higienização social. A sociedade escravista e também aquela que a sucedeu de imediato explorou e excluiu um grande número de pessoas. A Campinas do café, com o lento avançar do abolicionismo, da resistência escrava e das alforrias, abrigava um crescente número de negros e mestiços livres. Muitos libertos da área rural e de municípios vizinhos procuravam em suas ruas iluminadas a gás e percorridas por bondes uma oportunidade no restrito e concorrido mercado de trabalho livre, então em formação. Como seria de esperar em uma economia capitalista, nem todos conseguiam uma colocação e engrossavam a camada expropriada daqueles que viviam de trabalhos eventuais, da caridade pública e de outros expedientes mais ou menos lícitos. Nesse processo de formação da classe trabalhadora, os negros iriam arcar com a maior parte do ônus imposto pelo sistema, como escravos, como libertos. A liberdade em si não garantia oportunidades de trabalho e, muitas vezes, deixava o ex-escravo em situação de desamparo, livre para morrer de fome. Esse quadro desalentador alimentava muitas mazelas sociais, vistas nas ruas, lidas nos jornais. Entre as mulheres, a prostituição não poucas vezes se colocou como última saída na difícil luta pela sobrevivência. ${ }^{4} \mathrm{O}$ desemprego empurrou muitos jovens e adultos para as sendas do crime.

Essa camada esquecida e marginalizada da população, que vivia um cotidiano de privações e incertezas, não tinha muitas opções de moradia e via-se na contingência de aglomerar-se nos cortiços, numerosos na cidade, muitos deles no Jurumbeval. Quando associadas à prática da prostituição, coisa aliás muito comum na preconceituosa imprensa campineira, aquelas habitaçôes coletivas eram conhecidas então como "biombos". Para o maldizente "Máscara Negra”, responsável pela coluna "Carnaval da Vida" do Correio de Campinas,

os biombos são a vergonha da civilização. Piores que os cortiços do Conde D'Eu, na Corte, porque nos cortiços é apenas a miséria que se acouta, os biombos são os lugares certos onde a baixa devassidão vive e se oferece ao público amigo das Cleópatras de antigo eito. (Correio de Campinas, 23/10/1887, p. 1).

Os biombos tornaram-se uma das marcas registradas do Largo do Jurumbeval, tanto que uma das ruas vizinhas durante muitos anos teve o sugestivo nome de Rua Alegre. Essa característica local era motivo de numerosas reclamações de moradores que se sentiam prejudicados. Cenas consideradas ofensivas à moral pública eram recorrentemente denunciadas. Muitos campineiros cobravam ação mais 
contundente das autoridades para acabar com as imoralidades ( $G a$ zeta de Campinas, 2/10/1877, p. 2. Diário de Campinas, 16/4/1880, p. $1 ; 21 / 4 / 1886$, p. 2).

As preocupações em torno dos biombos não se limitavam às esferas da moral pública. Seus moradores e freqüentadores eram "naturalmente" vistos como perigosos à sociedade e o fato de abrigarem muitos libertos em seus pequenos cômodos tornava-os ainda mais suspeitos aos que consideravam seus métodos de ganhar a vida bastante questionáveis:

Daí resulta a aglomeração de libertos em biombos infectos onde se joga, onde a crápula se ostenta ignóbil e sem o mínimo resguardo, e onde são, de ordinário, recolhidos os frutos da gatunagem, os bens alheios subtraídos a seus legítimos donos. Para que não se multipliquem os habitantes desses antros, em que se aninham o vício e o crime, a perversidade e a devassidão, preciso é que as autoridades policiais lancem os seus olhos para essas espeluncas e procedam com todo o rigor para extinguí-las, usando das atribuiçôes que lhes confere a lei, no sentido de obrigar os seus assíduos freqüentadores a tomarem outro rumo, ganhando a vida honradamente. (Diário de Campinas, 21/11/1876, p. 2)

Com a iminente e inevitável chegada da abolição, esse discurso foi bastante sintomático porque era necessário fazer com que os ex-escravos se transformassem em responsáveis, regulares e dóceis trabalhadores assalariados (Chalhoub, 1986; Xavier, 1996).

Outras vias de se obter a subsistência eram condenadas, pois, além de diminuírem a oferta de mão-de-obra disponível no mercado, conferiam uma autonomia inconveniente a uma gente que se desejava controlar. Dessa maneira, ocorreu um recrudescimento no combate à vadiagem por parte da polícia e a criação de instituições para recolhimento dos inválidos e mendigos, instituições educativas por excelência, ao passo que se fazia a apologia do trabalho, único caminho para redimir a sociedade. Enquanto essa redenção não se consumava, urgia combater aqueles que fugiam aos padrões esperados de civilidade burguesa. Muitos sequazes das "condutas impróprias" como a pobreza e a vadiagem só poderiam mesmo, segundo pensamentos oficiais da época, viver nos execrados biombos e cortiços, que para alguns eram coisas diferentes, para outros, tudo a mesma coisa.

Dessa forma, nas décadas finais do século XIX e início do XX, com a passagem do trabalho escravo ao livre no Brasil, ocorreu em Campinas um processo de higienização e controle social, no qual a 
polícia exerceu a função pedagógica de "educadora", e as classes populares, vistas como perigosas, o papel de "educandos". Processo semelhante ao que estava ocorrendo em várias partes do território nacional, na Europa e nos Estados Unidos, com a formação da classe operária nas sociedades industriais (Bretas, 1997; Chevalier, 1978; Jones, 1971; Storch, 1985).

Em Campinas, na segunda metade do século XIX, os choques entre esses "educadores" e "educandos" foram constantes, o que, no entanto, não impediu relações por vezes contraditórias entre ambos. Vez ou outra a polícia promovia uma "caçada nos biombos", visando a combater a vadiagem:

Ontem [21/10/1885] o Sr. sub-delegado da Freguesia de Santa Cruz, fazendo-se acompanhar de praças, revistou todos os quartos e biombos existentes no Largo do Jurumbeval e rua do Caracol adjacente, encontrando diversas raparigas alforriadas que não se ocupavam em cousa alguma, uma delas até achava-se de cama e, entre as outras, fora encontrada uma escrava do Sr. Antonio José Machado, que em vez de cuidar do seu serviço de lavadeira, ali vadiava. Esta foi mandada a apresentar-se ao seu senhor e as outras intimadas para ocuparem-se em serviço honesto, sob pena de assinarem termo de bem viver. (Gazeta de Campinas, 22/10/1885, p. 2)

Como se pode notar, os biombos eram locais habitados por muitos forros e freqüentados por escravos, mesmo durante seu "expediente". De certa forma, a escrava encontrada no biombo tinha algum controle sobre o tempo de seu trabalho diário. Lavava a roupa no chafariz, mas sempre que possível fazia uma visita a suas conhecidas no biombo vizinho. ${ }^{6}$

Em 12 de abril de 1888, o subdelegado da Freguesia de Nossa Senhora da Conceição libertou vários indivíduos que haviam sido presos durante a "caçada que a polícia fez pelos biombos, a fim de reprimir a vagabundagem que neles costuma reunir-se". O Diário de Campinas criticou a ação policial que, juntamente com os tais vadios, prendeu várias "pessoas que têm ocupação honesta e que não devem ser vexadas", considerando que a polícia deveria continuar seu serviço higienizante de "limpar de vagabundos a cidade" sem, contudo, prejudicar os inocentes (Diário de Campinas, 13/4/1888, p. 2). O discurso deixava clara a associação de honestidade com uma vida de trabalho regular, regulado pela sociedade e seu tempo do capital.

A suspeição pairava sobre todas as moradias coletivas da cidade, mas, entre aquelas que existiam no Largo do Jurumbeval, nenhu- 
ma havia mais suspeita que o biombo do italiano Antonio Galhardo: "Ali há de dia e de noite ajuntamento de gente equívoca". Em 29 de agosto de 1880 foram presos em suas dependências José Tavares e os escravos Antonio Bueno e José Inocêncio. O próprio Galhardo, "proprietário desta tasca é um indivíduo que tem comparecido muitas vezes a polícia, ora por embriaguez, ora por turbulências e, ultimamente, perante o júri por crime de ferimentos". No dito biombo, segundo o Diário de Campinas, “junta-se uma récua de vagabundos, desordeiros e mulheres de ínfima casta, que a todo momento está pronta para praticar desordens”. Além dessas consideraçôes nada elogiosas atribuídas tanto a Galhardo quanto aos freqüentadores de seu concorrido estabelecimento, o famoso italiano envolvia-se, vez em quando, com a receptação de mercadorias de origem mais que duvidosa. De tanto falarem mal de sua pessoa ou porque sua situação estivesse um tanto complicada, Galhardo, muito contrariado, mudou-se para outro largo da cidade, o Carlos Gomes, onde estabeleceu novo biombo. Perseguido pela fama, permaneceu ali poucos meses, retornando ao seu antigo território: "O bem conhecido Antonio Galhardo, cáften da mais baixa extração, voltou a estabelecer o seu biombo no Largo do Jurumbeval, resultando as costumadas brigas e algazarras adubadas de palavrōes de fazer corar um morcego". O biombo de Galhardo, "foco do baixo vício e das cenas mais repelentes e ofensivas da moralidade pública", chegou a ser comparado a um verdadeiro câncer, que deveria ser extirpado definitivamente uma vez que seu proprietário era um incorrigível. Para tal cirurgia social convocava-se o delegado e seus ajudantes, que promoveriam uma "medida higiênica" aplaudida por todas as pessoas "sensatas" (Diário de Campinas, 23/4/1880, p. 1; 13/10/1880, p. $2 ; 28 / 1 / 1881$, p. $2 ; 13 / 7 / 1882$, p. $2 ; 5 / 11 / 1882$, p. 2. Gazeta de Campinas, 30/8/1880, p. 2).

Se por um lado a polícia promovia batidas e prisões nos biombos para combater a "vagabundagem" e promover a "higienização da sociedade", por outro, muitos de seus membros eram habituais freqüentadores daqueles espaços quase que públicos. Era comum encontrar policiais naquelas casas porque, afinal, elas estavam ou deveriam estar sob sua constante vigilância. A presença dos policiais no Largo do Jurumbeval, tantas vezes solicitada por muitos campineiros, acabou gerando descontentamento e até mesmo reclamações, já que os homens da lei muitas vezes não viam mal algum em unir o útil ao agradável. O célebre biombo de Antonio 
Galhardo era um de seus pontos de reunião preferidos, bem como os biombos de Martins Espanhol e do liberto Lúcio, "onde se juntam escravos e mulheres de condição reles, juntamente com praças de linha e de permanentes que fazem motim todos em parceria" (Diário de Campinas, 13/10/1880, p. 2; 20/5/1883, p. 2). Alguns furiosos vizinhos do Largo denunciaram: "Mulheres descompostas e sujeitos de má nota proferem as mais nauseabundas obscuridades. Temos visto também, e não é raro, alguns mantenedores da ordem entre a récua de vagabundos e de parceria com as Camélias sujas que ali se reúnem para escândalo da moralidade pública (...), e depõem contra a civilização da cidade" (Diário de Campinas, 6/ $10 / 1880$, p. 2).

Os responsáveis pela ordem na cidade deviam respeito aos regulamentos da corporação, mas eram também homens de carne e osso, sujeitos a erros e paixões. Às vezes, se bem que com certa regularidade, acabavam quebrando as regras, como o soldado João Palmeira. Ao cair da tarde de uma quarta-feira de julho de 1882, Palmeira entrou em um botequim para espantar o frio com a "canjebrina". Doses depois, sentindo-se aquecido e alegre, saiu de braço dado a uma "Vênus de Viela", provocando desordens. Diferenças de opinião e disputas entre policiais podiam resultar em cenas pouco amistosas. Num desses casos, à porta de um biombo, dois soldados "travaram-se de razōes e, depois de grande questão, puxaram os refles desafiando-se. Com a intervenção de diversos vizinhos não houve sério conflito". A participação ou a indiferença de muitos policiais com relação às "rixas e desordens" e ao "cinismo e a devassidão" no Largo do Jurumbeval fez com que se questionasse sua conduta: "É caso de policiarmos a polícia!" (Diário de Campinas, 13/7/1880, p. 2; 29/ 8/1880, p. 2; 28/11/1880, p. 2. Gazeta de Campinas, 24/6/1880, p. $1 ; 2 / 5 / 1880$, p. 2$) .7$

Dessa maneira, durante a segunda metade do século XIX em Campinas, a polícia serviu não apenas como instrumento legal de manutenção da ordem. Prestou-se também a uma função pedagógica/higienizadora que atingia de maneira contundente os mais pobres, reprimindo atos considerados reprováveis, impondo limites, ensinando como não se deveria agir. Os resultados, porém, não poucas vezes, foram inglórios, frutos da rica e imprevisível dinâmica do cotidiano, afinal muitos dos próprios policiais faziam parte desta parcela social que se pretendia reeducar, compartilhando seus hábitos e vivências. 


\section{Notas}

1. A teoria miasmática parte do princípio de que as doenças resultam de emanações morbíficas provenientes de substâncias orgânicas em decomposição, os chamados miasmas, e assim da necessidade de limpar, arejar, fazer o ar circular para restaurar ou manter a saúde. A idéia, com algumas modificações, dominou as teses médicas até o século XIX. Ver Corbin, 1987.

2. Ainda em plena atividade, conhecido popularmente como "Mercadão".

3. Assim neste texto, higiene social, higienização e higienização da sociedade são entendidas como açôes da polícia para coibir comportamentos considerados impróprios, ao mesmo tempo em que se buscava impor novas formas de conduta. Processo complexo que contou com os limites determinados pelos embates com os próprios "educandos". Afasto-me, dessa forma, de interpretaçóes calcadas em idéias foucaultianas do controle social.

4. Sobre o tema da prostituição entre os séculos XIX e XX, ver Esteves, 1989, e Rago, 1991.

5. Rua do Caracol, atual Rua Benjamim Constant. "Termo de Bem Viver” era um documento assinado por pessoas sem ocupação ("vadias" como então eram chamadas), comprometendo-se diante das autoridades policiais a arrumar emprego e a viver "decentemente" dentro de um prazo determinado, sob pena de voltar à prisão por vadiagem.

6. Sidney Chalhoub observou como os cortiços foram usados pelos escravos como verdadeiros "esconderijos na cidade". Cf. Chalhoub, 1990, p. 233-248. Ver também o interessante trabalho de Carlos Eugênio Líbano Soares, focalizando o Rio de Janeiro do século XIX. Cf. Soares, 1998.

7. A força policial de Campinas naqueles tempos, além de "deixar a desejar", na ótica de vários de seus moradores, era também considerada insuficiente para atender a uma cidade grande e com importante população escrava. Reiterados pedidos de aumento do contingente eram encaminhados ao governo provincial. Em 1882, criou-se o Corpo de Urbanos, uma polícia municipal que veio somar-se com o Corpo de Permanentes. Cf. Livro de Correspondências - 1881/1886, Arquivo da Câmara Municipal de Campinas, p. 22, 26 e 89.

\section{Referências bibliográficas}

BRETAS, M.L. Ordem na cidade: o exercício cotidiano da autoridade policial no Rio de Janeiro 1907-1930. Rio de Janeiro: Rocco, 1997.

CHALHOUB, S. Trabalho, lar e botequim. São Paulo: Brasiliense, 1986.

CHALHOUB, S. Visões da liberdade. São Paulo: Cia das Letras, 1990.

CORBIN, A. Saberes e odores. São Paulo: Cia das Letras, 1987.

ESTEVES, M.A. Meninas perdidas: os populares e o cotidiano do amor no Rio de Janeiro da Belle Époque. Rio de Janeiro: Paz \& Terra, 1989.

JONES, G.S. Outcast London: a study in the relationship between classes in Vitorian Society. Oxford: Oxford University, 1971. 
LAPA, J.R.A. A cidade: os cantos e os antros. Campinas 1850/1900. São Paulo: EDUSP, 1996.

LIVRO de Correspondências: 1881/1886. Campinas: Arquivo da Câmara Municipal de Campinas, s.d.

MARTINS, V. História de compra e venda: mercados e abastecimento urbano em Campinas, 1859/1908. 2001. Tese (Doutorado) - Faculdade de Filosofia, Letras e Ciências Humanas, Universidade de São Paulo, São Paulo.

RAGO, M. Os prazeres da noite: prostituição e códigos da sexualidade feminina em São Paulo (1890-1930). Rio de Janeiro: Paz \& Terra, 1991.

SOARES, C.E.L. Zungú: rumor de muitas vozes. Rio de Janeiro: Arquivo Público do Estado do Rio de Janeiro, 1998.

STORCH, R. O policiamento cotidiano na cidade vitoriana. Revista Brasileira de História, São Paulo, v. 5, n. 8/9, p. 7-33, 1985.

XAVIER, R.C.L. A conquista da liberdade: libertos em Campinas na segunda metade do século XIX. Campinas: CMU/Unicamp, 1996.

Jornais da cidade de Campinas

Correio de Campinas

Diário de Campinas

Gazeta de Campinas

O Constitucional 